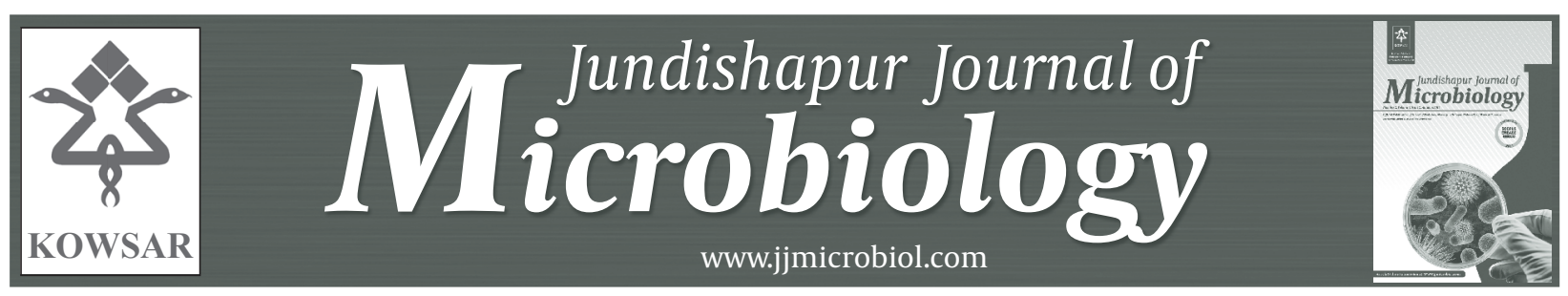

\title{
Diversity and Distribution Patterns of Airborne Microfungi in Indoor and Outdoor Hospital Environments in Khorramabad, Southwest Iran
}

\author{
Asghar Sepahvand ${ }^{1}$, Masoomeh Shams-Ghahfarokhi ${ }^{{ }^{*}}$, Abdolamir Allameh ${ }^{2}$, Mehdi Raz- \\ zaghi-Abyaneh $^{3}$ \\ ${ }^{1}$ Department of Medical Mycology, Faculty of Medical Sciences, Tarbiat Modares University, Tehran, IR Iran \\ ${ }^{2}$ Department of Biochemistry, Faculty of Medical Sciences, Tarbiat Modares University, Tehran, IR Iran \\ ${ }^{3}$ Department of Mycology, Pasteur Institute of Iran, Tehran, IR Iran \\ * Corresponding author: Masoomeh Shams-Ghahfarokhi, Department of Mycology, Faculty of Medical Sciences, Tarbiat Modares University, 14115-331, Teh- \\ ran, IR Iran.Tel.: +98-2182884505, Fax: +98-2182884555, E-mail: shamsm@modares.ac.ir and mshamsgh@yahoo.com
}

\begin{abstract}
A B S T R A C T
Background: Nosocomial fungal infections could arise from independent exposure to airborne spores of filamentous fungi existing in the hospital environment.

Objectives: The present study aimed to determine the mycoflora of indoor and outdoor environments of five major hospitals in Khorramabad, Iran.

Materials and Methods: Sampling of air was done from indoor and outdoor environments of wards, surroundings and green space of hospitals by settle plate method. To obtain the sample from surfaces, pre-moistened swabs with cotton-tipped sticks were applied on different surfaces (floor, the walls, windows, beds, trolleys, laryngoscope and angiography devices). Culture plates of air and surfaces on Potato Dextrose Agar (PDA) and Malt Extract Agar (MEA) were incubated in the dark at $28^{\circ} \mathrm{C}$ and examined daily for fungal colonies for two to three weeks. Fungal isolates were identified by a combination of their macroscopic and microscopic criteria after purification on isolation culture media.

Results: A total of 707 fungal colonies including, Penicillium (29.14\%), Cladosporium (24.04\%), Aspergillus (20.65\%), Fusarium (9.05\%), Alternaria (3.96\%), Rhodotorula (1.69\%), Cryptococcus neoformans (0.7\%) and other fungi (10.77\%) were isolated. All the examined high-risk parts of the hospitals were found to be contaminated by various fungi.

Conclusions: Aspergillus was the most prominent genus in Intensive Care Unit (ICU) and surgery, Cladosporium in Critical Care Unit (CCU), emergency and thalassemia, and Penicillium in orthopedic, emergency and neonatal sections. Among pathogenic yeasts, C. neoformans was isolated from ICU, surgery and orthopedic sections. The dimorphic fungal pathogen, Sporothrix schenckii, was reported from CCU. The isolated fungi specially the genera Aspergillus and Penicillium are potential threats for immunocompromised patients in the hospitals.
\end{abstract}

Keywords: Allergens; Fungi; Aeroallergens; Cladosporium; Penicillium; Hospitals

Copyright (c) 2013, Kowsar Corp.; Published by Kowsar Corp.

Article type: Research Article; Received: 11 Apr 2012, Revised: 23 May 2012, Accepted: 27 May 2012; DOI: 10.5812/jjm.5074

Implication for health policy/practice/research/medical education:

This is the first report on the isolation of Cryptococcus neoformans and Sporothrix schenckii from hospital environments in Iran which indicates facing new public health threats and therefore, the necessity to consider new approaches to monitor and control the exposure to the airborne microfungi.

Please cite this paper as:

Sepahvand A, Shams-Ghahfarokhi M, Allameh A, Razzaghi-Abyaneh M. Diversity and Distribution Patterns of Airborne Microfungi in Indoor and Outdoor Hospital Environments in Khorramabad, Southwest Iran. Jundishapur J Microbiol. 2013; 6(2):186-192. DOI: $10.5812 / \mathrm{jjm} .5074$

Copyright (C) 2013 Ahvaz Jundishapur University of Medical Sciences; Published by Kowsar Corp

This is an Open Access article distributed under the terms of the Creative Commons Attribution License(http://creativecommons.org/licenses/by/3.0), which permits unrestricted use, distribution, and reproduction in any medium, provided the original work is properly cited. 


\section{Background}

The history of indoor mold growth as a problem dates back to at least 5000 years ago when noticed in Biblical texts (1). Over 225 species of fungi have been reported from indoor environments which represent a few of the estimated 1.5 million species of fungi believed to exist (2). There is great concern about the potential health hazards of allergenic or toxigenic fungi (mycotoxins and/or secondary metabolites and volatile organic compounds) and their association with indoor air quality $(3,4)$. With the continual increase in the incidence of predisposing factors such as hematological malignancies, bone marrow and solid organ transplantation, chronic granolomatous disease and immunodeficiency syndromes, hospitals are facing the growing problem of invasive aspergillosis and other life threatening nosocomial fungal infections.

Since treatment of invasive fungal infections is difficult and the outcome is often fatal, preventing measures and thus, full understanding of the epidemiology of such devastating diseases are of major importance in the control programs (5). Nosocomial fungal infections could arise from inhalation of propagules (spores and hyphal fragments) of filamentous fungi which exist in hospital environment (6-8). These infections are predominantly caused by hyphomycetes such as Aspergillus species and rarely, by other fungi such as zygomycetes and dematiaceous moulds $(9,10)$. It has been shown that the primary ecological niche of important pathogenic fungi is soil and decaying materials; however, air plays a crucial role in spreading these fungi in the environment.

Indoor environments are potential sources of fungal spores, mycelia and harmful organic compounds such as mycotoxins which can be harmful to human health (11, 12). Fungal spores gradually settle out and the process of settling out and becoming airborne may be repeated for long periods of time, because the fungal spores can survive for months in suitable conditions. Low humidity, physical activity and the wind speed inside the buildings are effective in the release and distribution of spores (1). Potential sources of fungal spores in hospital air are inadequate filtration of outside air, accumulation of spores in dusts in air ducts, vacuum cleaning, carpeting, food spices, and soil of potted ornamental plants, flowers and fresh fruits $(5,13)$. Soil of ornamental and potted plants in hospitals as the reservoirs of pathogen fungi, beetles and ants (as fungi carriers), can play a role and cause the spread of hospital infections. Other sources of hospital acquired fungal infections are contaminated water and surfaces (9).

Beside the problems arising from direct inhalation of fungal spores, the spores of Aspergillus and Penicillium species can carry out different levels of mycotoxins which can be detected in air samples at high spore concentrations (1). The indoor moulds are usually originated from outdoor sources and their presence in large numbers or altered dominance indicates a source of colonization inside the hospitals (14). Recognition of fungal microflora from hospitals can help us to reduce problems associated with allergic respiratory diseases, fungal infections and systemic mycoses. Several studies from various parts of Iran such as Sari and Shiraz demonstrated that a wide array of microfungi could be present in air and water supplies as indoor hospital environments (15-17). However, a comprehensive study on indoor, outdoor and surface mycoflora of hospitals with special attention to their distribution in different sections has not been performed.

\section{Objectives}

The present study aimed to investigate the variety and percentage of microfungi in the air and surfaces of Khorramabad hospitals with emphasis on their locationbased distribution patterns.

\section{Materials and Methods}

\subsection{Sampling Sites}

General characteristics of Khorramabad hospitals selected for the current study (A, B, C, D, and E) are summarized in Table 1. Sampling was carried out during autumn 2009. Khorramabad, the capital of Lorestan, a western province of Iran, is situated at an altitude of 1170 meters above sea level and within the latitude and longitude of $33^{\circ} 29^{\prime} \mathrm{N}, 48^{\circ} 22$ 'E. The city is located at the folded zone of Zagros which the deposits are mainly a period of limestone and dolomite and has many rivers and springs. The climate is mountainous temperate and semi-arid with average annual rainfall of about $500 \mathrm{~mm}$ and a mean relative humidity of $60 \%$.

\begin{tabular}{llllll}
\hline \multicolumn{6}{l}{ Table 1. General Feature of Khorramabad Hospitals (A-E) Examined for Airborne Microfungi. } \\
\hline Hospital & Building Date & Specialty & Disinfectant & Total Floors & Air Conditioning (FAN) \\
\hline A & 1972 & General & Deconex & 2 & + \\
B & 1993 & Obstetrics \& Gynecology & Deconex & 2 & + \\
C & 1980 & Pediatrics & Deconex & 2 & + \\
D & 2004 & Heart & Deconex & 2 & + \\
E & 1991 & General & Deconex & 2 & + \\
\hline
\end{tabular}




\subsection{Air and Surface Sampling}

Sampling of air was done from indoor and outdoor environments of wards, surroundings and green space of hospitals by settle plate method according to Hoekstra et al. (18). Open lid Plastic plates (90 mm Dia.) containing Malt Extract Agar (MEA; E. Merck, Darmstadt, Germany) and Potato Dextrose Agar(PDA; E. Merck, Darmstadt, Germany) were placed in different sections of rooms in the mentioned hospital wards, at a height of about one meter above the floor where there was low or no air turbulence for an hour and exposed to room airflow. The sampling of outdoor air was performed by placing the open plates in various areas of hospital green space in a similar condition for indoor plates. To obtain samples from surfaces, pre-moistened swabs with cottontipped sticks were applied on different surfaces (floor, the walls, windows, beds, trolleys, laryngoscope, and angiography devices), were collected with an approximate size of 25 $\mathrm{cm} 2$, and immediately inoculated on to plates containing MEA and PDA media (19).

\subsection{Isolation and Identification of Fungi}

Culture plates of air and surfaces on PDA and MEA were incubated in the dark at $28{ }^{\circ} \mathrm{C}$ and were examined daily for fungal colonies for two to three weeks. After adequate sub-culturing on PDA, each single fungal colony was fi- nally purified by tip culture method. Fungal isolates were identified by a combination of their macroscopic and microscopic criteria as described in the mycology text books $(18,20,21)$. Only Aspergillus isolates were identified to the species level.

\section{Results}

In the present study, air and surface fungal contamination of five hospitals in Khorramabad city, the capital of Lorestan province, Southwest Iran, was evaluated by settle plate method in one step during autumn 2009. General features of the hospitals under study are summarized in Table 1 . All the hospitals were equipped with usual fans as air conditioning systems. They had two floors and used deconex as general disinfectant. A total of 165 plates of indoor and outdoor air as well as hospital room surfaces were studied.Overall, 761 microbial colonies including 712 fungal colonies and 49 bacterial colonies were isolated. Approximately, $81 \%$ of settle plates were positive for fungal growth. Table 2 shows total distribution of fungi recovered from settle plates in the five hospitals under study. Aside from five colonies of sterile mycelia, A total of 707 fungal colonies were isolated from 20 different genera belonging to both moulds (18 genera) and yeasts (two genera) ( Table 2 ).

Table 2. Distribution of Different Fungal Genera and Species Recovered From Khorramabad Hospitals (A-E).

\begin{tabular}{|c|c|c|c|c|c|c|}
\hline \multirow[t]{2}{*}{ Fungus } & \multicolumn{6}{|c|}{ Hospital, No. } \\
\hline & $\mathbf{A}$ & $\mathbf{B}$ & $\mathbf{C}$ & D & $\mathbf{E}$ & Total, No. (\%) \\
\hline Penicillium sp. & 32 & 33 & 87 & 8 & 46 & $206(29.14)$ \\
\hline Cladosporium sp. & 35 & 16 & 35 & 28 & 56 & $170(24.04)$ \\
\hline Aspergillus sp. & 16 & 17 & 30 & 46 & 37 & $146(20.65)$ \\
\hline Fusarium sp. & 38 & 13 & 0 & 0 & 13 & $64(9.05)$ \\
\hline Alternaria sp. & 3 & 1 & 17 & 2 & 5 & $28(3.96)$ \\
\hline Rhizopus sp. & 0 & 0 & 10 & 12 & 5 & $27(3.81)$ \\
\hline Aureobasidium sp. & 0 & 0 & 0 & 6 & 9 & $15(2.12)$ \\
\hline Rhodotorula sp. & 0 & 0 & 2 & 8 & 2 & $12(1.69)$ \\
\hline Mucor sp. & 0 & 0 & 7 & 2 & 0 & $9(1.27)$ \\
\hline Cryptococcus neoformans & 4 & 0 & 1 & 0 & 0 & $5(0.7)$ \\
\hline Chaetomium sp. & 0 & 0 & 0 & 5 & 0 & $5(0.7)$ \\
\hline Pseudallescheria boydii & 0 & 0 & 4 & 0 & 0 & $4(0.56)$ \\
\hline Ulocladium sp. & 0 & 0 & 0 & 0 & 4 & $4(0.56)$ \\
\hline Gliocladium sp. & 0 & 3 & 0 & 0 & 0 & $3(0.42)$ \\
\hline Paecilomyces sp. & 0 & 0 & 1 & 1 & 0 & $2(0.28)$ \\
\hline Epicoccum sp. & 0 & 0 & 0 & 2 & 0 & $2(0.28)$ \\
\hline Syncephalastrum sp. & 0 & 0 & 0 & 0 & 2 & $2(0.28)$ \\
\hline Sporothix schenckii & 0 & 0 & 0 & 1 & 0 & $1(0.14)$ \\
\hline Acremonium sp. & 0 & 0 & 0 & 0 & 1 & $1(0.14)$ \\
\hline Geotrichum sp. & 0 & 0 & 0 & 1 & 0 & $1(0.14)$ \\
\hline Contamination rate & $128(18.10)$ & $83(11.74)$ & $194(27.44)$ & $122(17.25)$ & $180(25.46)$ & $707(100)$ \\
\hline
\end{tabular}


Overall, Penicillium (29.14\%) was the most prominent fungal genus isolated followed by Cladosporium (24.04\%), Aspergillus (20.65\%), Fusarium (9.05\%) and Alternaria (3.96\%). These genera except for the Fusarium were isolated from all the hospitals under study.

The yeast genera i.e. Rhodotorula sp. and Cryptococcus neoformans comprised 8th and 10th frequent fungi with frequencies of 1.69 and $0.7 \%$, respectively. C. neoformans represented 27.77 (28\%) of the yeast colonies. Out of five C. neoformans colonies, four colonies were obtained from hospital A (indoor air in orthopedic surgery room: three colonies, outdoor air: one colony) and one colony in hospital C (NICU). The percentage of fungal colonies was reported in a descending order in the hospitals C (27.44\%), E (25.46\%), A (18.10\%), D (17.25\%) and B (11.74\%) ( Table 2 ). As an interesting result, a dimorphic fungus Sporothrix schenckii was reported one sample in hospital D.

Fungal contamination rate was higher in surfaces than indoors and outdoors. All the 20 fungal genera except Acremonium, Epicoccum and Paecilomyces, were reported from hospital surfaces, while 11 and 10 fungal genera were isolated from indoor and outdoor airs, respectively. Four genera i.e. Cladosporium, Penicillium, Fusarium and Aspergillus comprised the most prominent fungal groups isolated with a predominance of three latter genera for indoors, outdoors and surfaces, respectively. The current study findings demonstrated that the highest rate of Aspergillus colonies existed in the surgery section of hospital D.

Comparing the results of this study showed, in terms of fungal growth, the hospital surfaces of C, E (100\%), A, D (91.66\%) and B (50\%) were contaminated with the genus Aspergillus. The highest rate of indoor contamination belonged to hospitals $\mathrm{C}>\mathrm{E}>\mathrm{B}>\mathrm{D}>\mathrm{A}$, respectively. Identification of the genus Aspergillus as one of the most important agents of nosocomial fungal infections at species level showed the presence of five species as indoor and outdoor contaminants (Figure).

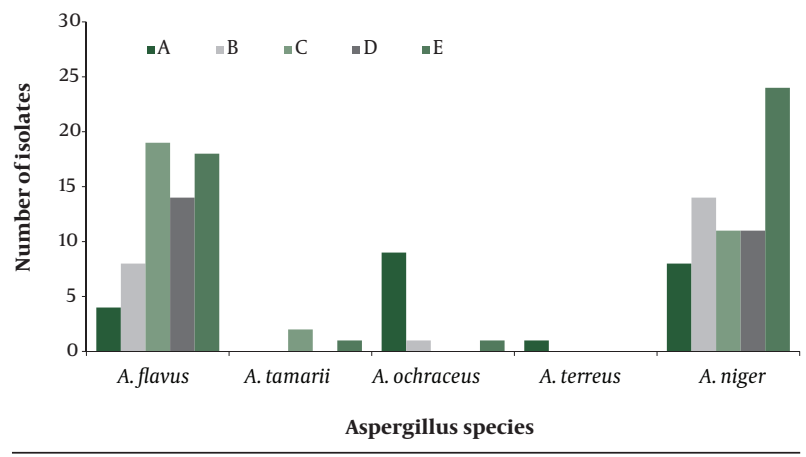

Figure. Aspergillus Species Recovered From Indoor and Outdoor Environments of Khorramabad Hospitals (A-E)

Of 146 Aspergillus colonies, A. niger (68/146) was the most frequent species followed by A. flavus (63/146), A. ochraceus (11/146), A. tamarii (3/146) and A. terreus (1/146). The highest rate of $A$. niger colonies was in hospital E, the surfaces, particularly in the operating room. Only A. niger and A.flavus were isolated from all hospitals under study. These species were reported from both air (indoors and outdoors) and surfaces, while the other species were isolated only from surfaces and in one case from indoors for A. ochraceus.

Table 3 shows indoor and surfaces fungal contamination of high-risk sections of hospitals under study. In all sections except for neonatal and thalassemia, surfaces were reported to be more contaminated than indoors. Overall, all the sections were contaminated with fungal isolates at least for the genera Aspergillus, Cladosporium and Penicillium. Aspergillus was the most prominent genus in ICU and surgery, Cladosporium in CCU, emergency (men) and thalassemia, and Penicillium in orthopedic, emergency (women) and neonatal sections. Human pathogens, C. neoformans, was isolated from ICU, surgery and orthopedic sections, Alternaria from ICU, surgery, emergency, neonatal and thalassemia, Pseudallescheria boydii and Mucor from neonatal, S. schenckii from CCU and Fusarium from surgery and emergency wards.

\section{Discussion}

This study assessed the presence of filamentous fungi and yeasts in air (indoor and outdoor) and surfaces of five hospitals in Khorramabad, Iran. The environments of all hospitals were contaminated with different fungi from 20 genera which the majority of them belonged to the hyaline Hyphomycetes. Several studies confirmed the diversity in the type and recovery rates of fungi from indoor and outdoor environments of hospitals. In the present study, the fungal genera Penicillium, Cladosporium, Aspergillus and Fusarium had the highest frequency among the total fungi.

A main reason is that Aspergillus, Penicillium and Cladosporium produce numerous small and light spores that generally remain in the air, whereas Alternaria, Ulocladium and some other fungal genera produce fewer, larger and heavier spores which tend to have faster settling (10). Hedayati et al. reported Cladosporium, Aspergillus, Alternaria and Penicillium as the dominant fungi in the air and on the supplies of operating rooms of 17 hospitals in Mazandaran, Iran (16). In the review of airborne fungi in two hospitals in Shiraz, Iran, Pakshir et al. reported the genera Cladosporium, Penicillium and Aspergillus as the most common contaminants of indoor air (17).

Among five Aspergillus species reported in the current study, A. niger and A. flavus were isolated from all the hospitals with a frequency higher than those of other species. This is in accordance with the reports of other researchers on predominance of these species in hospital environments $(17,22)$. 
Table 3. Total Diversity and Distribution Patterns of Fungi Isolated From Indoor and Surfaces of High-Risk Sections of Khorramabad Hospitals (A-E).

\begin{tabular}{|c|c|c|c|c|c|c|c|c|c|c|c|c|c|c|c|c|}
\hline & \multicolumn{2}{|c|}{$\begin{array}{l}\text { Thalas- } \\
\text { semia }\end{array}$} & \multicolumn{2}{|c|}{ Neonatal } & \multicolumn{2}{|c|}{$\begin{array}{l}\text { Emer- } \\
\text { gency } \\
\text { (Women) }\end{array}$} & \multicolumn{2}{|c|}{$\begin{array}{l}\text { Emergen- } \\
\text { cy (Men) }\end{array}$} & \multicolumn{2}{|c|}{$\begin{array}{l}\text { Orthope- } \\
\text { dic }\end{array}$} & \multicolumn{2}{|c|}{ Surgery } & \multicolumn{2}{|c|}{ CCU } & \multicolumn{2}{|c|}{ ICU } \\
\hline & 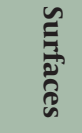 & 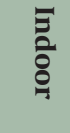 & $\begin{array}{l}\mathscr{E} \\
\stackrel{\mathscr{D}}{\mathscr{D}}\end{array}$ & छี & है & $\begin{array}{l}\Xi \\
\vdots \\
\vdots\end{array}$ & 气 & छัّ & 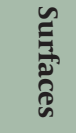 & 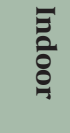 & $\frac{n}{\tilde{2}}$ & छี & 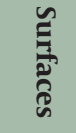 & \begin{tabular}{l}
$\Xi$ \\
\hdashline \\
\hdashline
\end{tabular} & 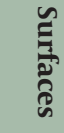 & छั \\
\hline Penicillium sp. & 2 & 12 & 8 & 40 & 24 & 13 & 4 & 0 & 16 & 2 & 10 & 7 & 2 & 3 & 13 & 5 \\
\hline Cladosporium sp. & 14 & 11 & 2 & 2 & 21 & 12 & 6 & 8 & 4 & 0 & 4 & 6 & 13 & 5 & 23 & 2 \\
\hline Aspergillus sp. & 2 & 7 & 5 & 1 & 8 & 3 & 8 & 2 & 2 & 0 & 35 & 7 & 6 & 1 & 24 & 7 \\
\hline Fusarium sp. & 0 & 0 & 0 & 0 & 1 & 0 & 2 & 0 & 0 & 0 & 2 & 1 & 0 & 0 & 0 & 0 \\
\hline Alternaria sp. & 0 & 1 & 1 & 0 & 0 & 0 & 0 & 5 & 0 & 0 & 1 & 0 & 0 & 0 & 3 & 1 \\
\hline Rhizopus sp. & 3 & 0 & 0 & 0 & 0 & 0 & 0 & 3 & 0 & 0 & 2 & 0 & 0 & 0 & 0 & 0 \\
\hline Aureobasidium sp. & 0 & 0 & 0 & 0 & 0 & 0 & 0 & 0 & 0 & 0 & 2 & 0 & 3 & 0 & 0 & 0 \\
\hline Rhodotorula sp. & 0 & 0 & 0 & 1 & 3 & 0 & 0 & 0 & 0 & 0 & 2 & 3 & 0 & 2 & 0 & 0 \\
\hline Mucor sp. & 0 & 0 & 7 & 0 & 0 & 0 & 0 & 0 & 0 & 0 & 0 & 0 & 0 & 0 & 0 & 0 \\
\hline Cryptococcus neoformans & 0 & 0 & 0 & 0 & 0 & 0 & 0 & 0 & 0 & 2 & 0 & 1 & 0 & 0 & 1 & 0 \\
\hline Chaetamium sp. & 0 & 0 & 0 & 0 & 0 & 0 & 0 & 0 & 0 & 0 & 0 & 1 & 4 & 0 & 0 & 0 \\
\hline Pseudallscheria boydii & 0 & 0 & 4 & 0 & 0 & 0 & 0 & 0 & 0 & 0 & 0 & 0 & 0 & 0 & 0 & 0 \\
\hline Ulocladium sp. & 0 & 0 & 0 & 0 & 0 & 0 & 0 & 0 & 0 & 0 & 4 & 0 & 0 & 0 & 0 & 0 \\
\hline Gliocladium sp. & 0 & 0 & 0 & 0 & 3 & 0 & 0 & 0 & 0 & 0 & 0 & 0 & 0 & 0 & 0 & 0 \\
\hline Paecilomyces sp. & 0 & 1 & 0 & 0 & 0 & 0 & 0 & 0 & 0 & 0 & 0 & 0 & 0 & 1 & 0 & 0 \\
\hline Epicoccum sp. & 0 & 0 & 0 & 0 & 0 & 0 & 0 & 0 & 0 & 0 & 0 & 0 & 0 & 2 & 0 & 0 \\
\hline Syncephalastrum sp. & 0 & 0 & 0 & 0 & 0 & 0 & 0 & 0 & 0 & 0 & 2 & 0 & 0 & 0 & 0 & 0 \\
\hline Sporothrix schenckii & 0 & 0 & 0 & 0 & 0 & 0 & 0 & 0 & 0 & 0 & 0 & 0 & 0 & 1 & 0 & 0 \\
\hline Acremonium sp. & 0 & 0 & 0 & 0 & 0 & 0 & 0 & 1 & 0 & 0 & 0 & 0 & 0 & 0 & 0 & 0 \\
\hline Geotricum sp. & 1 & 0 & 0 & 0 & 0 & 0 & 0 & 0 & 0 & 0 & 0 & 0 & 0 & 0 & 0 & 0 \\
\hline Contamination rate & 22 & 32 & 27 & 44 & 60 & 28 & 20 & 19 & 22 & 4 & 64 & 26 & 28 & 15 & 64 & 15 \\
\hline
\end{tabular}

In a study by Okten and Akan in the pediatric unit of a hospital in Turkey, 65 species belonging to 16 fungal genera were identified, and among them Cladosporium (33.6\%) was prominent genus followed by Alternaria (22.5\%) and Penicillium (20.3\%) (23). Aside from high adaptability to different environmental conditions especially low water activity and $\mathrm{pH}$ as well as producing a vast number of small air borne conidia, it has been shown that their ability to live on a wide array of substrates even different fabrics and plastics (cotton, polyester, polyethylene, polyurethane) that are routinely used in hospitals, may account in part for massive distribution and long term survival of Aspergillus and Penicillium species in the hospital environments (24-26).

The current study did not isolate any A. fumigatus from the hospitals under study. Panagopoulou et al. reported A. fumigatus as the third prevalent Aspergillus species after A. niger and A. flavus from the air of the hospitals in
Greece (9). Pakshir et al. did not achieve to isolate any $A$. fumigatus isolate from the indoor environments of Shiraz hospitals in Iran (17). According to the current study and the majority of other studies performed in Iran, it can be concluded that $A$. fumigatus may be substituted by $A$. flavus as the predominant fungal pathogen of the genus Aspergillus in hospital environments (15-17). Considering the presence of Penicillium isolates as the most dominant isolated fungi, the awareness of infections, and allergies caused by this fungus it should be mentioned that they can be easily mistaken in some cases due to major similarities with Aspergillus infections (27).

In the present study, in addition to Aspergillus sp. and Zygomycetes (Rhizopus and Mucor) isolated, members of the genera Fusarium, Rhodotorula, Alternaria, Acremonium and $P$. boydii have received special attention as emerging nosocomial fungal pathogens (28). In a recent study evaluating indoor fungal flora of a French tertiary 
care hospital, $94-100 \%$ of the samples of tap water were contaminated with Fusarium species including F. oxysporum and F. dimerum (29). This shows that indoor opportunistic fungal pathogens such as $F$. oxysporum may particularly adapt to aquatic environment. In the present study, C. neoformans and Rhodotorula sp. were isolated as dominant yeast species, while Candida albicans or other Candida species were not encountered. The main reason is that Candida is predominantly of endogenous origin and does not have a major external source other than the hands of health-care workers or relatives or contaminated devices (13).

C. neoformans was isolated from hospitals $\mathrm{A}$ and $\mathrm{C}$ as the oldest among five hospitals under study. It is probably due to the presence of the fungus in pigeon's excreta nesting under the garret ceiling of these old hospitals where it can survive for two years or more in suitable conditions (30). C. neoformans is one of the most important agents of fatal meningitis in immunocompromized patients in the hospital. After inhalation of infective propagules and colonization in lungs, the disease progresses rapidly and finally leads to death in the majority of cases.

Although S. schenckii is not considered as an agent of life-threatening nosocomial infections, its unusual isolation from CCU in the present study indicates that any fungus which resides in soil can be entered to hospital environment possibly via the flower jars and vases dedicated by patients' relatives and visitors. Another important aspect of the presence of Aspergillus and Penicillium species in the hospital environments is their potential threats for public health via producing carcinogenic mycotoxins. Even though mycotoxins are not released in the atmosphere, they are carried out by conidia and hyphal fragments and can be detected in air samples at high spore concentrations (1).

Since conidia and most fragments are smaller than 5 $\mu \mathrm{m}$, they can penetrate deeply in the respiratory system, where they are destroyed in healthy individuals by cells of immune system. But cell residuals remain on the surface of epithelia and possibly enter the blood stream. The amount of mycotoxins entering the body this way is quite low, comparing to acute intoxication caused by eating contaminated food. However, long term exposure to indoor mycotoxins for the people who spend majority of their life in closed environments can cause chronic or sub-chronic intoxications (11).

The present study demonstrated the presence of filamentous fungi and yeasts in air (indoor and outdoor) and surfaces of five hospitals in Khorramabad city, as potential health threats for immunocompromised patients. Besides Aspergillus, Penicillium and some other cosmopolitan moulds as allergens, mycotoxin producers and pathogens, isolation of unusual fungi in the hospital environments i.e. C. neoformans and S. schenckii in the current study indicated the exposure to new threats and therefore, the necessity to consider new approaches to monitor and control the exposure to the air borne fungal conidia. Using the HEPA filters for high-risk rooms, a modification on arrangement and distance from green spaces to wards and control of food and flower taken by the patients' visitors and relatives to the hospital are suggested measures which can reduce the chance of fungal spore inhalation in hospital environments.

\section{Acknowledgements}

The authors wish to thank the personnel of Khorramabad hospitals for their invaluable cooperation in sample preparation and Mrs. Razeghi for her helpful assistance.

\section{Financial Disclosure}

All authors declare that they have no conflict of interest.

\section{Funding/Support}

This work was supported financially by Research Deputy of Tarbiat Modares University.

\section{Authors' Contribution}

None declared.

\section{References}

1. Fog Nielsen K. Mycotoxin production by indoor molds. Fungal Genet Biol. 2003;39(2):103-17.

2. McGinnis MR. Indoor mould development and dispersal. Med Mycol. 2007;45(1):1-9.

3. Douwes J, Thorne P, Pearce N, Heederik D. Bioaerosol health effects and exposure assessment: progress and prospects. Ann Occup Hyg. 2003;47(3):187-200.

4. King N, Auger P. Indoor air quality, fungi, and health. How do we stand? Can Fam Phys. 2002;48(2):298-302.

5. VandenBergh MF, Verweij PE, Voss A. Epidemiology of nosocomial fungal infections: invasive aspergillosis and the environment. Diagn Microbiol Infect Dis. 1999;34(3):221-7.

6. Brenier-Pinchart MP, Lebeau B, Quesada JL, Mallaret MR, Borel JL Mollard A, et al. Influence of internal and outdoor factors on filamentous fungal flora in hematology wards. Am J Infect Control. 2009;37(8):631-7.

7. Hellgren UM, Hyvarinen M, Holopainen R, Reijula K. Perceived indoor air quality, air-related symptoms and ventilation in Finnish hospitals. Int J Occup Med Environ Health. 2011;24(1):48-56.

8. Lee LD, Hachem RY, Berkheiser M, Hackett B, Jiang Y, Raad II. Hospital environment and invasive aspergillosis in patients with hematologic malignancy. Am J Infect Control. 2012;40(3):247-9.

9. Panagopoulou P, Filioti J, Petrikkos G, Giakouppi P, Anatoliotaki M, Farmaki E. Environmental surveillance of filamentous fungi in three tertiary care hospitals in Greece. $J$ Hosp Infect. 2002;52(3):185-91.

10. Vonberg RP, Gastmeier P. Nosocomial aspergillosis in outbreak settings. J Hosp Infect. 2006;63(3):246-54.

11. Cabral JP. Can we use indoor fungi as bioindicators of indoor air quality? Historical perspectives and open questions. Sci Total Environ. 2010;408(20):4285-95

12. Rolle-Kampczyk U, Müller A, Diez U, Rehwagen M, Schwenke A Metzner G, et al. Mycotoxins in house dust-an underestimated problem? Mycotoxin Res.. 2000;16:100-4.

13. Munoz P, Burillo A, Bouza E. Environmental surveillance and other control measures in the prevention of nosocomial fungal 
infections. Clin Microbiol Infect.. 2001;7(Suppl 2):38-45.

14. Crook B, Burton NC. Indoor moulds, sick building syndrome and building related illness. Fungal Biol Rev. 2010;24(3-4):106-13.

15. Hedayati M, Mayahi S, Movahedi M, Shokohi T. Study on funga flora of tap water as a potential reservoir of fungi in hospitals in Sari city, Iran. J Med Mycol. 2011;21(1):10-4.

16. Hedayati M, Mohammadpour R. A survey on the mycological contamination of the air and the equipment of operating rooms of 17 hospitals. J Med Facul Guilan Uni Med Sci. 1999;8(19):56-61.

17. Pakshir K, Shekarkhar G, Mostagnie S, Sabayan B, Vaghefikia A Monitoring of airborne fungi in two general hospitals in Shiraz, Southern Iran. Iran J Med Sci. 2007;32(4):240-4.

18. Samson R, Hoekstra E, Frisvad J. Centraalbureau voor Schimmelcultures (CBS). 2000;

19. Chazalet V, Debeaupuis JP, Sarfati J, Lortholary J, Ribaud P, Shah P, et al. Molecular typing of environmental and patient isolates of Aspergillus fumigatus from various hospital settings.J Clin Microbiol. 1998;36(6):1494-500.

20. de Hoog G, Guarro J, Gene J, Figueras M. Centraalbureau voor Schimmelcultures Atlas of Clinical Fungi. 2000.

21. Frey D, Oldfield R, Bridger R. Wolf Medical Publications A Colour Atlas of Pathogenic Fungi. 1985.

22. Sautour M, Dalle F, Olivieri C, L'Ollivier C, Enderlin E, Salome E. A prospective survey of air and surface fungal contamination in a medical mycology laboratory at a tertiary care university hospital Am J Infect Control. 2009;37(3):189-94.

23. Okten S, Asan A. Airborne fungi and bacteria in indoor and outdoor environment of the Pediatric Unit of Edirne Government Hospital. Environ Monit Assess. 2012;184(3):1739-51.

24. Klich MA. Health effects of Aspergillus in food and air Toxicol Indust Health. 2009;25(9-10):657-67.

25. Krishnan S, Manavathu EK, Chandrasekar PH. Aspergillus flavus: an emerging non-fumigatus Aspergillus species of significance Mycoses. 2009;52(3):206-22.

26. Neely AN, Orloff MM. Survival of some medically important fung on hospital fabrics and plastics. J Clin Microbiol. 2001;39(9):3360-1.

27. Lyratzopoulos G, Ellis M, Nerringer R, Denning DW. Invasive infection due to Penicillium species other than P. marneffei. J Infect. 2002;45(3):184-95.

28. Pfaller M, Wenzel R. Clinical Mycology. 2009

29. Sautour M, Edel-Hermann V, Steinberg C, Sixt N, Laurent I, Dalle F. Fusarium species recovered from the water distribution system of a French university hospital. Int J Hyg Environ Health. 2012;215(3):286-92.

30. Fisher F, Cook N. New York: W.B Saunders Company Fundamentals of Diagnostic Mycology. 1998. 